- Osseo-integrated dental implants are a successful way of supporting missing units.

- Implant fracture is a relatively uncommon complication.

- Implant placement and restoration require careful consideration in order to avoid such complications.

- When implant fracture occurs the fixture may be left in situ, removed, or salvaged if the fracture occurs at a favourable level.

\title{
A review of the aetiology and management of fractured dental implants and a case report
}

\author{
P. Virdee ${ }^{1}$ and K. Bishop ${ }^{2}$
}

\begin{abstract}
Osseo-integrated dental implants offer a predictable treatment for the replacement of missing teeth. ${ }^{1-3}$ Despite the high success, complications can occur such as loss of integration, peri-implantitis and mucositis as well as mechanical problems. The latter includes screw loosening and more significantly fracture of the implant itself. As implant use is increasing, practitioners are more likely to face, and have to deal with, such complications. This report describes the management of a patient with a fractured Brånemark fixture in the maxilla. The likely causes are discussed and the treatment options highlighted together with the decision making process which lead to the final management.
\end{abstract}

\section{CASE REPORT}

A 52-year-old male was referred to the Department of Restorative Dentistry in 1999 requesting the restoration of the missing left maxillary first and second molars (26 and 27). These teeth had been extracted several years previously possibly due to endodontic or structural problems. The patient had no relevant medical history, was a non-smoker with no history of parafunction but was employed in a high stress occupation.

After discussions with the patient and undertaking a full evaluation including radiographic assessment and study models, it was decided to restore the edentulous space using an implant-retained

\footnotetext{
'Specialist Registrar in Restorative Dentistry. Department of Periodontology, Eastman Dental Hospital, 256 Gray's Inn Road, London, WC1X 8LD; ${ }^{2}$ Consultant in Restorative Dentistry, Department of Restorative Dentistry, Morriston Hospital, Swansea, SA6 6NL Correspondence to: Miss Parminder Virdee Email:Parminder.Virdee@uclh.nhs.uk
}

\section{Refereed Paper}

Accepted 25 April 2007

DOI: $10.1038 /$ bdj.2007.948

${ }^{\circ}$ British Dental Journal 2007; 203: 461-466 bridge. Subsequently, two $15 \mathrm{~mm}$ Mark II Brånemark regular platform fixtures were inserted in 1999 under a local anaesthetic using a traditional twostage procedure. In January 2000 two $17^{\circ}$ angulated abutments (Fig. 1) (Nobel Biocare UK Ltd, Nobel House, The Grand Union Office, Packet Boat Lane, Uxbridge UB8 2GH, UK) were placed and a twounit porcelain fused to metal restoration inserted a month later. The bridge conformed to the existing canine-guided occlusion with posterior disocclusion in protrusion. It was retained with gold slotted screws inserted at $10 \mathrm{Ncm}$ torque.

Regular standard reviews were uneventful until June 2005, when prosthetic screw loosening was noted but no problems were detected with the abutments. At this time the original prosthetic screws were replaced with titanium 'Torquetite' screws (Nobel Biocare UK Ltd, Nobel House, The Grand Union Office, Packet Boat Lane, Uxbridge UB8 2GH, UK) at the recommended increased insertion torque of $15 \mathrm{Ncm}$. Unfortunately, the patient presented four months later complaining of bridge loosening.
The prosthesis was removed again when it was observed on this occasion that the distal fixture (27) had fractured at the alveolar bone margin with the abutment screw still intact within the abutment (Fig. 2).

On inspection, the cross-sectional surface of the fractured fixture appeared homogenous with no obvious gross voids or other signs of manufacturing imperfections. There were however a number of obvious cracks across its diameter.

As an immediate measure, an acrylic bridge retained by temporary cylinders was provided, with canine guidance, posterior disocclusion in protrusion and light contacts in intercuspal position (ICP); the latter being coincidental with retruded contact position (RCP). No attempt was made to engage the temporary cylinder on the fractured implant surface at this stage.

An intra-oral peri-apical radiograph (Fig. 3) obtained at this time showed no change in bone levels at the non-fractured fixture (26). However, there appeared to be further bone loss associated with the fractured implant (27). 


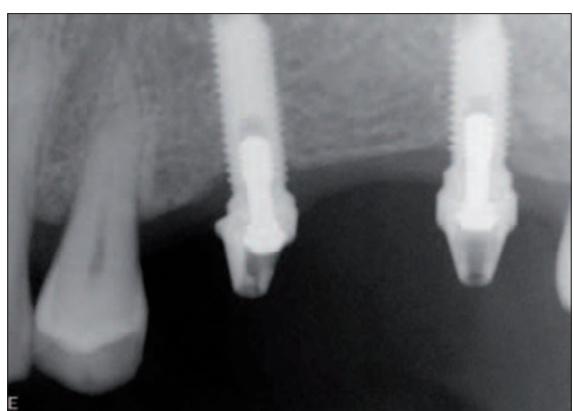

Fig. 1 Peri-apical radiograph following abutment placement in January 2000

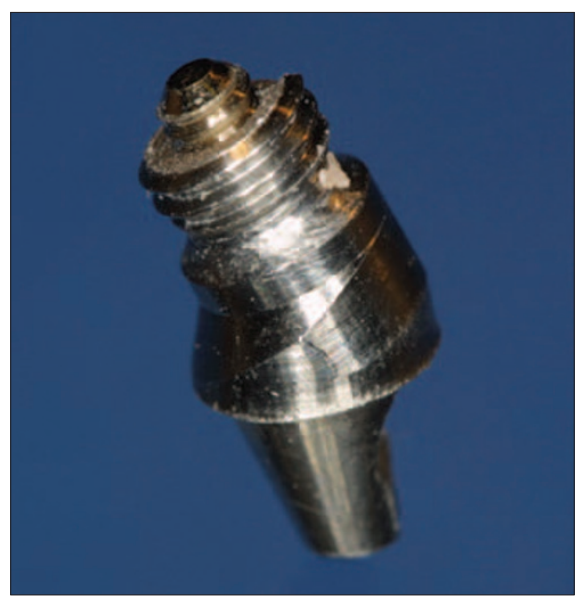

Fig. 2 Removed coronal portion of fractured fixture still attached to abutment

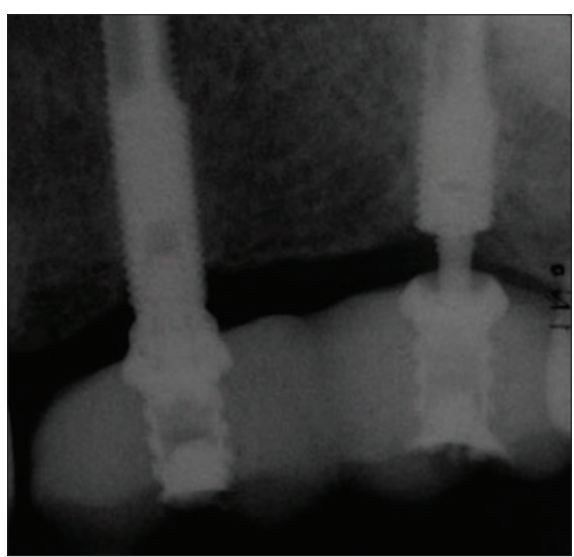

Fig. 3 Peri-apical radiographs of implants following removal of coronal portion of fractured fixture and the placement of a temporary bridge

At this stage the following management options were considered and discussed with the patient:

1. Accept the missing second molar, and provide a new single unit restoration to replace the first molar using the intact implant

2. Provide a replacement implant retained bridge supported by two fixtures, using the intact fixture and either:

- Remove and replace the fractured fixture
- Salvage the fractured fixture

- Accept the fractured fixture and insert a new implant more mesially, resulting in a cantilever two implant supported bridge design

3. Provide an implant retained bridge using the intact fixture together with an additional two implants to provide a three fixture supported restoration. This could be achieved by placing an additional fixture together with either:

- Removal and replacement of the fractured fixture

- Salvaging the fractured fixture.

A decision was made to salvage the fractured fixture and provide a three implant retained bridge by placing an additional implant between the existing two fixtures.

As a result, under a local anaesthetic, the fractured fixture was exposed by a punch excision of the overlying mucosa. The fractured surface was then refaced to provide a flattened area at right angles to the long axis of the fixture so a connecting abutment would more easily locate. This recontouring was accomplished by use of the Endmill Bur (Nobel Biocare UK Ltd, Nobel House, The Grand Union Office, Packet Boat Lane, Uxbridge UB8 2GH, UK), which consists of cutting flutes and a central guide pin for positioning in the fixture thread to ensure correct location of the cutting flutes. The bur was used with a slow speed of 20 revs. per minute and a $40 \mathrm{Ncm}$ torque, with copious irrigation and lubrication (Fig. 4). An additional Brånemark, Mark IV, $15 \mathrm{~mm}$ long, wide platform fixture with an enhanced titanium oxide surface (Tiunite Nobel Biocare UK Ltd, Nobel House, The Grand Union Office, Packet Boat Lane, Uxbridge UB8 2GH, UK) was placed off-centre, between the existing implants.

A customised abutment was also placed on the fractured fixture at this time. This latter component incorporated a $17^{\circ}$ Multi-Unit abutment with a customisable gold prosthetic screw (Fig. 5), which was shortened to an appropriate length. Beneath the abutment a customised cylindrical titanium connecting abutment was inserted which replaced the fractured portion of the fixture. This connecting abutment also had a TiUnite surface.
A $17^{\circ}$ Multi-Unit abutment was placed on the implant in the first molar site and a straight $1 \mathrm{~mm}$ Multi-Unit abutment on the more central wide platform fixture (Figs 6 and 7).

Impressions were recorded with abutment copings and an acrylic screw retained interim bridge inserted using temporary cylinders. The bridge conformed with the canine guided lateral excursions and had light contacts in ICP with posterior disocclusion in protrusion.

A definitive bridge was subsequently fabricated from a milled titanium framework and inserted three months later (Fig. 8). This restoration copied the occlusal features of the temporary restoration. During the period between insertion of the temporary and definitive restorations, no further complications were observed.

The patient has been followed-up regularly and no problems have developed.

\section{DISCUSSION}

The fracture of a dental implant is an uncommon occurrence with most studies reporting an incidence of between $0-1 \%$ in Brånemark fixtures (Table 1). ${ }^{2-10}$ An early study reported an incidence of $3.5 \%{ }^{1}$ but this may have been due to the inclusion of implants inserted whilst the technique was being developed and the longer maximum follow up period of 15 years. ${ }^{1}$ Implant fracture occurs at all levels of the fixture, usually at around five years after insertion, and with the majority in the maxilla. ${ }^{1}$ The literature also reports a $1.9 \%$ fracture rate in 157 ITI implants (Straumann AG, Waldenburg, Switzerland) that were followed for up to two years after loading. ${ }^{11}$ Case reports and case series of fractured ITI, ${ }^{12,13}$ and Core-Vent (Zimmer Dental, 1900 Aston Avenue, Carlsbad, CA 92008-7308.USA) fixtures also exist. ${ }^{14,15}$

\section{POTENTIAL CAUSES OF IMPLANT FRACTURE}

The main factors which may lead to a risk of implant fracture appear to be:

- Bending overload ${ }^{16}$

- Manufacturing imperfections ${ }^{8}$

- Restoration design ${ }^{17}$

- Accuracy of fit of restoration ${ }^{1}$

- Implant numbers, dimensions and positioning $^{17-18}$

- Marginal bone loss ${ }^{1}$

- Occlusion and parafunctional habits $^{8,12,17}$

- Chemical factors. ${ }^{19}$ 


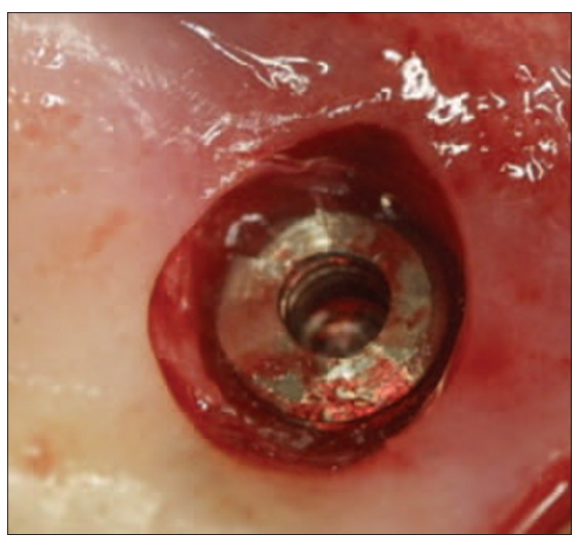

Fig. 4 Refaced, smooth surface of retained portion of fractured fixture

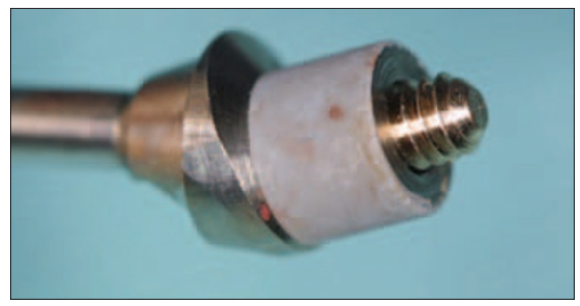

Fig. 5 Customised abutment incorporating connecting abutment and gold screw

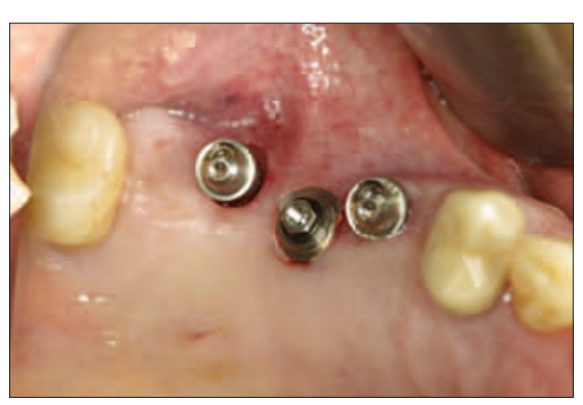

Fig. 6 Abutments secured onto resultant three fixtures

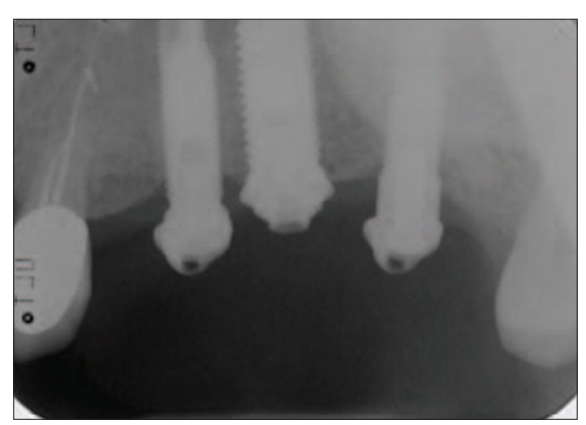

Fig. 7 Peri-apical radiograph after salvaging the fixture, the placement of additional implant and abutment connection

\section{Bending overload}

Bending overload is defined as the load on an implant-supported prosthesis that exerts a bending moment on the fixture cross-section at the crestal bone level, leading to marginal bone loss and/or implant fatigue fracture. ${ }^{16}$ Previous case series and reports, involving scanning electron micrograph (SEM) investigations of fractured implant surfaces, revealed fatigue striations $s^{10,20-21}$ consistent with those obtained in vitro when implants were cyclically loaded to fracture..$^{20}$ This would suggest that bending overload and resultant fatigue failure is the usual mode of fracture of an implant. Some of the SEMs of the fractured implant in this case had a similar appearance to thosein previously reported cases (Fig. 9).

\section{Manufacturing imperfections}

There are no reports of implant fractures due to manufacturing imperfections, with previously reported SEMs of fractured implant surfaces failing to show any characteristic defects. ${ }^{8,10,12,20-21}$

Similarly, the SEM of the fractured implant surface in this case revealed uniformity of the microstructure and a homogenous grain structure which would suggest an absence of any manufacturing error (Fig. 9).

\section{Restoration design}

Cantilever design bridges increase the stress upon an implant, and have been found to be associated with fractured implants (Table 2)..$^{8,10,17,20,22}$ Fractured fixtures also appear to occur more frequently in single implant supported, single unit restorations (Table 2). ${ }^{10,17,12-}$ ${ }^{14,22}$ Implant fractures associated with a combined dento-implant supported restoration have also been reported (Table 2). ${ }^{5,15,17,21}$ The reports relating fractured implants to restoration design either are retrospective or this information has been missing, or are case reports. It is therefore unknown if the distribution of implant fractures, with regard to restoration type, is simply a reflection of the cohorts investigated. However, from these reports it does appear fractured implants in partially edentulous cases are often associated with cantilever, single tooth, or dento-implant supported restorations.

Although the bridge in this case was not of cantilever design, molar units are larger than the supporting fixture platforms so some cantilever forces may have developed within the restoration. For this reason some clinicians advocate the placement of two fixtures for each molar unit replaced..$^{23}$ A decision was made to reduce the potential for a cantilever effect in the new restoration by placing an additional fixture.

\section{Accuracy of fit of restoration}

Previous studies have shown implant fracture in partially edentulous fixed prostheses occurs with older, less passively fitting prostheses. ${ }^{1,24-26}$ A non-passive fit can also lead to screw loosening (Table 2). 4,8,10,17,21

Although this patient's original bridge appeared clinically acceptable, it was constructed using a cast metal framework which may have increased the risk of a less than optimum fit. In addition screw loosening had been observed immediately prior to the implant fracturing. However screw loosening has been reported in 5-25\% of patients during routine implant review. ${ }^{4,27}$ As such this is not, by itself, necessarily a sign of impending implant fracture. However, if it does occur the prostheses should be re-evaluated as well as other design and occlusal features. ${ }^{28}$

It is anticipated that the new bridge, which was constructed from a milled titanium framework, provides a more accurately fitting prosthesis by eliminating errors that may arise in the casting process. ${ }^{29}$ The bridge was completed by veneering with composite rather than porcelain to avoid possible firing deformation and also to make the restoration more serviceable in the future.

Implant numbers, dimensions and positioning Theoretical models suggest the effects of loading on implant supported restorations can be significantly reduced by the placement of additional implants, the use of wider platform fixtures and the avoidance of implants being positioned in a straight line. ${ }^{17-18}$ In previous reports, fixtures have fractured when a straightline arrangement of the implants has been adopted (Table 2)..$^{8,17,20}$ Therefore, in this case, a decision was made to support the new bridge with three implants rather than two, with the additional central implant being a wide platform and positioned off centre in an attempt to improve load distribution (Fig. 6).

\section{Marginal bone loss}

Recently, figures for acceptable bone loss associated with fixtures of various designs and loading protocols have been proposed. ${ }^{30}$ However, in edentulous arches, the mean acceptable maximum value for marginal bone loss around Brånemark Mark II implants restored following the original two stage 


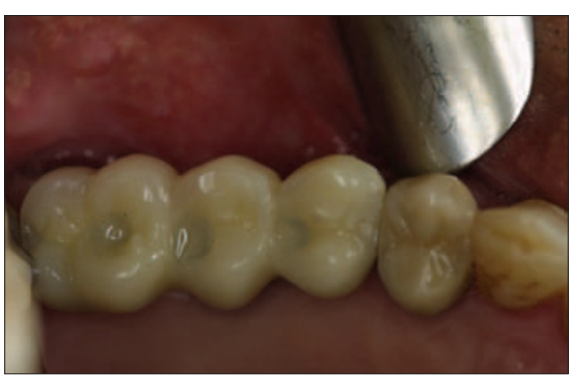

Fig. 8 Definitive bridge in place

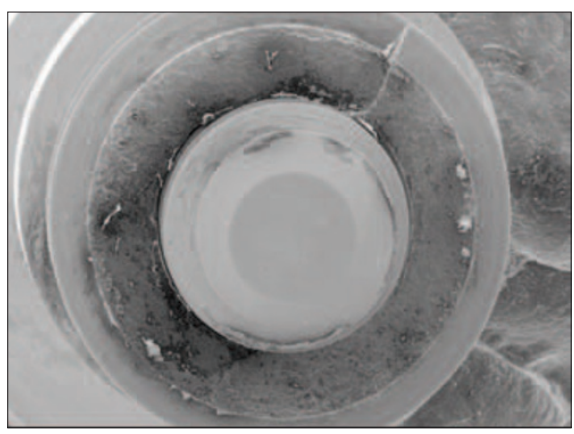

Fig. 9 Scanning electron micrograph of fractured section of removed coronal portion of fractured fixture $\times 15$

protocol is $1.2 \mathrm{~mm}$ during healing and the first year after bridge connection, and $0.1 \mathrm{~mm}$ annually thereafter. ${ }^{1,31}$ Lekholm and co-workers reported a mean bone loss of $0.7 \mathrm{~mm}$ over a ten-year period in partially edentulous jaws. ${ }^{3}$

In the case of this patient, the marginal bone level around the fractured fixture was eventually up to the fifth thread, if both the removed and retained portions of the fractured fixture are considered. At the intact fixture (26) site, there was no change in marginal bone level since initial loading. At the latter site this was acceptable, whilst at the fracture site the amount of bone loss was excessive.
Increased marginal bone loss has also been associated with implant fractures (Table 2). ${ }^{8,10,12,14,17,20-21}$ In the 15-year study by Adell et al. in 1981, fixtures that had rapid bone loss of approximately $3 \mathrm{~mm}$ a year all presented with eventual mechanical complications such as screw, fixture and bridge fractures. ${ }^{1}$ This would suggest that any rapid marginal bone loss should be investigated for possible mechanical complications, including fixture fracture.

Increased marginal bone loss has also been associated with excessive loading and this may occur within a year of the problem being initiated., ${ }^{4}, 32$ Typically, this is seen on radiographs, as a crater-like pattern of bone loss around the fixture. ${ }^{33}$ In this case, until the time of fracture, there had been no evidence of excessive bone loss at any of the implant sites.

However, it is unclear whether marginal bone loss is a cause or an effect of implant fracture, or if they are both consequences of unfavourable loading. There is also the possibility that when an implant begins to fracture, it becomes secondarily infected which causes the accelerated marginal bone loss.

Whatever the explanation, any significant bone loss at the crestal level increases the unsupported coronal length of the implant, increasing the crown to implant ratio, resulting in the fixture becoming more at risk to bending forces.

Where excessive bone loss has occurred, the weaker hollow portion of the implant, apical to the abutment screw may become the fulcrum for the loading. This area is obviously weaker and as such, at this stage the implant may become particularly vulnerable to fracture..$^{20,22}$ This may particularly be the case in fixtures whose design features incorporate a significant void in this region. ${ }^{12-14}$

Histological analysis of fractured implant portions retained in bone reveal a high degree of osseointegration in the retained portion, apical to marginal bone levels. ${ }^{12,15}$ In this case, radiographic examination of the retained portion showed close apposition of bone around the implant periphery, apical to the marginal bone level, indicating a high degree of osseointegration.

\section{Occlusion and parafunctional habits}

Implant fracture has been associated with parafunction but there is no significant scientific evidence to support this increased risk (Table 2). ${ }^{8,12,17}$ Although the patient reported no history of parafunction, and there were no clinical signs suggesting any habit, parafunction can not be eliminated as a contributory factor. The patient reported that his natural upper left molars had been extracted since they were heavily broken down and this may have been a consequence of parafunction. The patient was also in a high stress profession which may also have contributed to the problem.

During the new reconstruction, however, care was taken to avoid excessive occlusal forces by ensuring that all restorations achieved light contacts in ICP with canine guidance and disocclusion on protrusion and excursions. The staggered placement of three implants, with the additional implant being wide

Table 1 Incidence of dental implant fracture

\begin{tabular}{|c|c|c|c|c|}
\hline Study & Fixture sample & Restoration & Follow up (years) & Fractured implants \\
\hline Adell et al., $1981^{1}$ & 1997 & Fixed, complete & $1-15$ & $3.5 \%$ \\
\hline Zarb and Scmitt, $1990^{2}$ & 274 & Fixed, complete & $4-9$ & $0.0 \%$ \\
\hline Naert et al., $1992^{4}$ & 564 & Fixed, complete & $0.4-6.9$ & $0.5 \%$ \\
\hline Pylant et al., $1992^{5}$ & 102 & Fixed, partial & $0.5-4$ & $1.0 \%$ \\
\hline Tolman and Laney $1993^{6}$ & 1778 & Fixed/ overdenture, complete/ partial & Up to 6.5 & $0.2 \%$ \\
\hline Henry et al., $1996^{7}$ & 107 & Single tooth & Up to 5 & $0.0 \%$ \\
\hline Balshi $1996^{8}$ & 4045 & Fixed partial & Up to 5 & $0.2 \%$ \\
\hline Allen et al., $1997^{9}$ & 236 & Fixed/ overdenture, complete/ partial & Up to 6 & $0.0 \%$ \\
\hline Lekholm et al., $1999^{3}$ & 461 & Fixed partial & $5-10$ & $0.4 \%$ \\
\hline Eckert et al., $2000^{10}$ & 4937 & Complete, partial & Up to15 & $0.6 \%$ \\
\hline
\end{tabular}


Table 2 Factors associated with fractured implants

\begin{tabular}{|c|c|c|}
\hline Study & Fracture (reference sample size) & Factors associated with fractured fixtures \\
\hline \multirow[b]{2}{*}{ Adell et al., $1981^{1}$} & \multirow[b]{2}{*}{69 (1997) } & $70 \%$ rigid bridge design (less optimal fit) \\
\hline & & $\begin{array}{l}\text { If rapid marginal bone loss seen (about } 3 \mathrm{~mm} \text { in one year), eventual } \\
\text { mechanical complications like screw, fixture and bridge fractures resulted }\end{array}$ \\
\hline Naert et al., $1992^{4}$ & $3(564)$ & $67 \%$ screw loosening preceding fracture \\
\hline Pylant et al., $1992^{5}$ & $1(102)$ & Combined dento-implant supported restoration \\
\hline \multirow{9}{*}{ Rangert et al., $1995^{12}$} & \multirow{9}{*}{39 total (estimated 10,0000) } & $90 \%$ molar or premolar \\
\hline & & $82 \%$ straight line implant placement \\
\hline & & $69 \%$ where increased leverage forces \\
\hline & & $56 \%$ bruxism/ heavy occlusal force \\
\hline & & 59\% preceding mechanical complications (i.e. loose screw) \\
\hline & & $>3$ threads bone loss in $36 \%$ prior to, $92 \%$ after fracture \\
\hline & & 10 complete prostheses \\
\hline & & 11 partial prostheses, of which $21 \%$ combined dento-implant supported \\
\hline & & 18 single tooth implants, of which all molar \\
\hline \multirow{5}{*}{ Balshi, $1996^{8}$} & \multirow{5}{*}{$8(4045)$} & $100 \%$ straight line implant arrangement \\
\hline & & $100 \%$ parafunction \\
\hline & & $100 \%$ bone loss after fracture \\
\hline & & $75 \%$ in posterior region \\
\hline & & $88 \%$ multiple implant partial ceramo-metal \\
\hline Piattelli et al., $1998^{14}$ & 4 (unknown) & $75 \%$ single implant, single unit \\
\hline \multirow{5}{*}{ Eckert et al., $2000^{10}$} & \multirow{5}{*}{28 total (4937) } & $96 \%$ screw loosening preceding fracture \\
\hline & & typically marginal bone loss (cupping) \\
\hline & & 10 complete prostheses \\
\hline & & 13 partial prostheses, of which $69 \%$ had a cantilever pontic \\
\hline & & 5 single tooth implants, of which all molars \\
\hline
\end{tabular}

platform, also potentially distributed the occlusal loads more favourably. An acrylic occlusal splint has also been provided for night time wear.

\section{Chemical factors}

Titanium implant components adsorb hydrogen in the biological environment and it has been suggested that this makes them more brittle and prone to fatigue. ${ }^{19}$ A further case report of a fractured titanium implant supporting a nickel-chromium-molybdenum alloy restoration, suggested cytotoxic nickel ions may have accelerated bone resorption. The authors suggested that this resulted in the implant becoming more prone to bending and fatigue fracture. ${ }^{13}$
However, there is currently little additional evidence to support these suggestions as major contributors to implant fracture.

\section{Planning considerations}

A decision was made to retain the fractured implant as a significant length of fixture had maintained osseointegration and its removal would have resulted in bone loss. Furthermore, there is a possibility that any replacement fixture may not have integrated.

Salvaging a fractured dental implant is not always feasible. In this case the fracture level was favourable, with sufficient screw threads available in the retained portion to locate the Endmill bur's guide pin and to secure an abutment screw. If this had not been the case then retaining the fractured fixture as a viable functioning unit would not have been possible.

\section{CONCLUSION}

Dental implants are a predictable method of replacing missing teeth. When complications occur, consideration should be given to potential causes and how they can be overcome.

Implant fracture is a rare cause of failure but when it does occur it can present significant treatment planning and technical challenges. When considering remedial treatment following a fracture consideration should be given 
to the implant numbers, their design and features as well as their position. In addition the design of any restoration should aim to reduce unfavourable loading, particularly cantilever forces and ensuring a passively fitting framework.

1. Adell R, Lekholm U, Rockler B, Branemark PI. A 15 -year study of osseointegrated implants in the treatment of the edentulous jaw. Int J Oral Surg 1981; 10: 387-416.

2. Zarb G A, Scmitt A. The longitudinal clinica effectiveness of osseointegrated dental implants: the Toronto study. Part III: Problems and complications encountered. J Prosthet Dent 1990 64: 185-194.

3. Lekholm U, Gunne J, Henry P et al. Survival of the Brånemark implant in partially edentulous jaws: a 10 year prospective multicentre study. Int J Oral Maxillofac Implants 1999; 14: 639-645.

4. Naert I, Ouirynen $M$, van Steenberge D, Darius P. A study of 589 consecutive implants supporting complete fixed prostheses. Part II: Prosthetic aspects. J Prosthet Dent 1992; 68: 949-956.

5. Pylant T, Triplett R G, Key M C, Brunsvold M A. A retrospective evaluation of endosseous titanium implants in the partially edentulous patient. Int J Oral Maxillofac Implants 1992; 7: 195-202.

6. Tolman D E, Laney W R. Tissue-integrated dental prostheses: the first 78 months of experience at the Mayo Clinic. Mayo Clin Proc 1993; 68: 323-331.

7. Henry P J, Laney W R, Jemt T et al. Osseointegrated implants for single tooth replacement: a prospective 5-year multicentre study. Int J Oral Maxillofac Implants 1996; 11: 450-455.

8. Balshi T J. An analysis and management of fractured implants: a clinical report. Int J Oral Maxillofac Implants 1996; 11: 660-666.

9. Allen P F, McMillan A S, Smith D G. Complications and maintenance requirements of implant-supported prostheses provided in a UK dental hospital. Br Dent J 1997; 182: 298-302.
10. Eckert S E, Meraw S J, Cal E, Ow R K. Analysis of incidence and associated factors with fractured implants: a retrospective study. Int J Oral Maxillofac Implants 2000; 15: 662-667.

11. Levine R A, Clem D S, Wilson T G et al. Multicentre retrospective analysis of the ITI system used for single tooth replacements: results of loading for two or more years. Int J Oral Maxillofac Implants 1999; 14: 516-520.

12. Piattelli $A$, Scarano $A$, Piattelli $M$ et al. Hallow implants retrieved for fracture: a light and scanning electron microscope analysis of 4 cases. J Periodonto/ 1998; 69: 185-189.

13. Tagger Green N, Machtei E E, Horwitz J, Peled M. Fracture of dental implants: a literature review and report of a case. Implant Dent 2002; 11: 137-143.

14. Ibbott C G. In vivo fracture of a basket type osseointegrating dental implant: a case report. Int J Oral Maxillofac Implants 1989; 4: 255-256.

15. Brunel G, Armand S, Miller N, Rue J. Histologic analysis of a fractured implant: a case report. Int J Periodontics Restorative Dent 2000; 20: 521-526.

16. Rangert $B$, Jemt $T$, Jörnéus $L$. Forces and moments on Branemark implants. Int J Oral Maxillofac Implants 1989; 4: 241-247.

17. Rangert $B$, Krogh P H J, Langer B, Roekel N V. Bending overload and implant fracture: a retrospective clinical analysis. Int J Oral Maxillofac Implants 1995: 10: 326-334.

18. Rangert B, Sullivan R. Biomechanical principles preventing prosthetic overload induced by bending. Nobelpharma News 1993; 7: 4-5.

19. Yokoyama K, Ichikawa T, Murakami H, Miyamoto $Y$ Asaoka K. Fracture mechanisms of retrieved titanium screw thread in dental implant. Biomaterials 2002: 23: 2,459-2,465.

20. Morgan M J, James D F, Pillar R M. Fractures of the fixture component of an osseointegrated implant. Int J Oral Maxillofac Implants 1993; 8: 409-414.

21. Velasquez-Plata D, Lutonsky J, Oshida Y, Jones R. A close up look at an implant fracture: a case report. Int J Periodontics Restorative Dent 2002; 22: 482-491.

22. Gibney K. Fracture of the body of an implant and its management - a case history. Br Dent J 2004; 197: 615-617.

23. Bahat 0 , Handelsman M. Use of wide implants and double implants in the posterior jaw: a clinical report. Int J Oral Maxillofac Implants 1996; 11:379-386.

24. Carr A B, Steward R B. Full-arch implant framework casting accuracy: preliminary in vitro observation for in vivo testing. J Prosthodont 1993; 2: 2-8.

25. Meijer H J, Kuiper J H, Starmans F J, Bosman F. Stress distribution around dental implants: Influence of superstructure, length of implants, and height of mandible. J Prosthet Dent 1992; 68: 96-102.

26. Watanabe F, Unu I, Hata Y, Neuendorff G, Kirsch A Analysis of stress distribution in a screw-retained implant prosthesis. Int J Oral Maxillofac Implants 2000; 15: 209-218.

27. Wie H. Registration of localisation, occlusion and occluding materials for failing screw joints in the Brånemark implant system. Clin Oral Implants Res 1995; 6: 47-53.

28. Saba S. Occlusal stability in implant prosthodontics - clinical factors to consider before implant placement. J Can Dent Assoc 2001; 67: 522-526.

29. Ortorp A, Jemt T, Back T, Jalevik T. Comparisons of precision of fit between cast and CNC-milled titanium implant frameworks for the edentulous mandible. Int J Prosthodont 2003; 16: 194-200.

30. Wennstrom J L, Palmer R M. Proceedings of the 3rd European Workshop on Periodontology. In Lang N, Karring T, Lindhe J (eds) Implant dentistry. Berlin: Quintessense 1999.

31. Albrektsson T, Zarb G, Worthington P, Eriksson A $R$. The long-term efficacy of currently used dental implants: a review and proposed criteria of success. Int J Oral Maxillofac Implants 1986; 1: 11-25.

32. Quirynen $M$, Naert I, van Steenberge D. Fixture design and overload influence marginal bone loss and fixture success in the Brånemark system. Clin Oral Implants Res 1992; 3: 104-111.

33. Duyck J, Ronold H J, Van Oosterwyck H et al. The influence of static and dynamic loading on marginal bone reactions around osseointegrated implants: an animal experimental study. Clin Oral Implants Res 2001; 12: 207-218. 